\title{
Analyzing Conversational Reasoning
}

\author{
Merrilee H. Salmon \& Colleen M. Zeitz University of Pittsburgh
}

Keywords: Discourse, argumentation, conversational analysis, pragmatics, implicit premises, shared reasoning.

\begin{abstract}
This work discusses an empirical study of reasoning as it occurs in conversations. Reasoning in this context has features not usually accounted for in standard methods for describing argumentation (e.g., Toulmin, (1964), Toulmin, Rieke, and Janik (1984)). For example, insufficient attention has been paid to challenges which can be used to shift the ground of an argument and to the development of multiple conversational grounds. Moreover, even though the value of cooperative efforts in building arguments is widely recognized, more needs to be said about analyzing co-constructed arguments. This empirical work was primarily descriptive and concerned with how people construct arguments in conversations, but one goal of the study was to lay groundwork for comparing the quality of reasoning in conversations which differ with respect to whether the arguments they contain are primarily the contributions of individuals or are genuinely co-constructed arguments.
\end{abstract}

\section{Introduction}

Until recently, studies of socially shared cognition focused on how information is shared but treated reasoning as a solitary activity. Studies typically portray a reasoner who, albeit influenced by socially induced biases and pressures, weighs the evidence for a claim and accepts or rejects it on the basis of the evidence. In contrast to this picture of the solitary reasoner, a dialogic approach illuminates the work of Rescher (1977), van Eemeren and Grootendorst (1992), Blair and Johnson (1987), Freeman (1991), Walton (1992), and Jacobs and Jackson (1992). All of these authors examine situations in which one participant argues for a conclusion while the other opposes it. Such "pro and con" dialogic reasoning can occur in debates between several parties and also in the "internal dialogue" of a single reasoner, often with the assistance of "prompts" (Voss, 1991). Toulmin, Rieke, and Janik (1984) recognize that "rebuttals" can be suggested either by the proponent of the argument or someone else. Rebuttals are points "that might undermine the force of the supporting arguments" (1984; p. 95; emphasis in original). All of these authors take a pragmatic approach to reasoning. They examine actual reasoning as well as ideal standards for reasoning. We share this pragmatic concern, and agree especially with Jacobs and Jackson's portrayal of communication "as a tapestry into which the argument itself has been woven" which therefore requires analysis if the argument is to be understood. 
The various goals of the participants in a dialogue shape different patterns of dialogic reasoning. "Pro and con" arguments that resemble zero-sum games in which a gain for one participant results in a loss for the other receive the most attention, but other forms of dialogues are common. Participants in a dialogue sometimes want to accommodate each other's divergent views and to reach compromises. Some cooperative dialogues aim merely to expose several sides of an issue in order to eliminate misunderstanding and find a common ground. A cooperative dialogue can reveal hidden complexities and allow more subtle and detailed presentation of opposing viewpoints. Kuhn, Weinstock, and Flaton (1994) propose that social exchanges among jurors may provide a corrective for the weaknesses they have documented in the reasoning of individual jurors. Even when no resolution is reached, which may often be the case (Schiffrin (1985)), a cooperative dialogue can be useful. Our empirical studies revealed cooperative features in many conversations about controversial issues. Conversations which apparently were more concerned with cooperation than with "making points" were distinguished by more frequent turn-taking and by a higher proportion of utterances that were completed by another person or simply left unfinished.

Philosophers of science likewise have shown increasing concern with dialogic reasoning in science. Rescher's dialectical model for analyzing scientific inquiry and other sorts of factual investigations draws on arguments presented in a court of law, i.e., the judicial model that Toulmin favors. Rescher characterizes the scientific investigator as an "advocate who sets out to propound and defend a certain thesis" (1977; p. 110). In his model, the social engagement of the investigator is similar to that of an attorney who argues a case against an adversary, under the scrutiny of a judge and jury. The scientific community, broadly conceived, serve as judge and jury in cases of scientific inquiry.

Both Kitcher (1991, 1992) and Longino (1992) discuss the social character of reasoning in the context of science. Each examines the reasoning of scientists in groups, and offers an account of shared inference in which participants' contributions go beyond offering pro and con arguments for a single position. For example, Kitcher discusses the situation in which one group member refuses to abandon a line of thought no longer attractive to others in the group. The others might regard the assumptions required to support the questionable position as untenable, the experiment to support it a failure, or the statistical support for it inadequate. The member who refuses to yield the position, Kitcher says, still serves the group by freeing colleagues to pursue new leads. Ultimately, Kitcher maintains, scientists' reasoning should be judged as a product of their research group rather than of individuals.

Most scientific research is a group activity. From the perspective of scientists engaged in various experiments in support of a larger project, their research includes conversations concerning the conduct and results of the enterprise. Kitcher (1991) examines various rhetorical strategies that scientists use to overcome potential objections and obtain a suitable hearing. Kitcher (1992) acknowledges the social character of knowledge-including how we reason to scientific conclusions-while resisting extreme forms of sociological skepticism. (See also Leff (1978) for a treatment of rhetoric as a knowledge-building process.)

Longino (1992) locates the social character of inference in background assumptions that scientists share as a result of their scientific training. Along with laboratory skills and factual information, scientific training instills many assumptions that influence scientists' later judgments about the bearing of particular evidence on their hypotheses. These background assumptions, Longino notes, though "largely invisible to practitioners within the community," can be articulated and criticized by the scientific community and the larger public (1992; p. 207).

Not surprisingly, ordinary conversations-especially those that concern controversial issues that involve both factual judgements and considerations of the best action to take-exhibit many of the same features that Kitcher and Longino find in scientific conversations. Participants in conversations use rhetorical strategies to present their ideas; they anticipate and respond to objections, using various strategies to criticize or support one another. Each participant shares some explicit beliefs and assumptions with other participants. Each is influenced by others while trying to adjust a set of beliefs to the new situation. Some stubbornly hold a position; others are quick to yield. Our experiments attempted to expose such features of ordinary conversations so that we could see how they affect participants' reasoning. We recognize, of course, that dialogues in scientific investigations differ importantly from many ordinary conversations in which differing opinions are expressed. In the former, proof or refutation of a thesis is a major goal, if not the chief goal. Even when competitions strongly motivate scientific activity, the professed goal is the truth above all other prizes. In conversation, social considerations that encourage cooperation-as well as "antisocial" refusal to cooperate in order to have one's own way-frequently override questions of proof or even truth. Schiffrin (1985) notes the scarcity of positive outcomes of arguments outside of scientific contexts. In fact, she tries to explain why arguments are so often unproductive, though she does not offer empirical evidence for her claim that resolutions are rarely reached.

Despite the discouraging analysis of Schiffrin, we believe that most college students successfully construct and evaluate arguments in their everyday lives. At the same time, only a small group of these students are able to reconstruct, represent, and evaluate arguments in the manner required by classes in logic (Henle (1962); Johnson-Laird (1983)). Puzzled by the apparent disappearance in the classroom of a naturally occurring skill, we designed our empirical study of conversational reasoning with the hope of exploiting insights thus gained to improve the teaching and evaluation of reasoning.

\section{The Empirical Study}

The initial study, reported in Resnick, Salmon, and Zeitz (1991), videotaped students' discussion of whether the United States should continue to use and 
develop nuclear power. The students were all enrolled in a course entitled "Philosophy, Science, and Public Policy." Groups of three, all male or all female, were instructed to reach some consensus within the twenty minutes allotted for discussion. The first goal of the study was to develop a set of categories for analyzing these conversations, particularly with respect to conversational moves that affected reasoning (see also Resnick, Salmon, Zeitz, Wathen, and Holowchak (1993)).

In an attempt to minimize subjective interpretations of what the subjects said, we adopted the following procedures for transcribing the conversations, supplying anaphoric references, filling in minor gaps, and categorizing the subjects' utterances. The transcriber of the videotapes supplied punctuation, including marks signifying ellipses, and we checked the transcriptions against the tapes. The few problematic cases were settled by viewing tapes again. No further steps were taken to secure objectivity in transcription. Working independently with transcriptions only, we and others who had not viewed the videotapes supplied anaphorical references, dates, and times, and tried to clarify other, seemingly minor, ambiguities. Agreement on this task was sufficiently high to obviate the need for additional checking. Any significant rewording of what subjects said was inserted into the transcript following the original utterance, and marked by a "T." After these details of translation were settled, we tried to label the subjects' utterances with respect to their roles in the reasoning process.

We were less concerned with correctness of the subject's reasoning than with how (and how long) they defended or yielded their positions, and how they adjusted their claims in response to other participants in the conversations. When the subjects made claims and offered reasons for them, we used the categories premise and conclusion in our analysis. The subjects, however, also made concessions, offered examples, asked questions, challenged and attacked views. In response, subjects denied claims, conceded points, gave further examples, and restated positions, often shifting emphasis by intensifying utterances or making them less strong. In some conversations, individual subjects tended to present textbook-style arguments-such as instances of statistical syllogism or modus tollens. In others, they supported or attacked points made by other participants in more-or-less structured ways. These various moves formed the basis of our classification.

At the time of our first study (1989-90), Toulmin's scheme for analyzing arguments in ordinary language was the most widely used (Toulmin (1964), modified and expanded in Toulmin, Rieke, and Janik (1984).) Others have modified Toulmin's account to make it more appropriate for analyzing dialectical argumentation. (See especially Freeman 1991, who draws on both Rescher's 1977 insights and Blair and Johnson (1987).)

\section{The Structure of Reasoning in Conversation}

Toulmin (1964) proposed adopting a jurisprudence model of reasoning to provide more subtle and appropriate distinctions than formal logic permitted. His familiar analysis employs the categories of claims, data, warrants, modal qualifiers, and conditions of exception or rebuttals. Ultimately, we defend a different set of categories because our purpose is different from Toulmin's. He wanted to show that not every "good" argument is formally (deductively) valid by showing that generalizations that "warrant" drawing conclusions are of several types. We are interested in capturing dynamic features of conversational reasoning that can account for the possibility of co-constructed arguments. No unique "natural" system for classifying the components of arguments is available. Classificatory systems are instruments for specific purposes and should be judged accordingly.

Toulmin recognized the implicit character of various types of generalizations used as warrants or backing in many ordinary-language arguments. Because conversations provide mechanisms for exposing implicit beliefs, they provide a natural context in which to examine unstated assumptions. Participants in conversations typically share some specific factual information and many general beliefs and values. If conversational partners follow Grice's conversational maxims (1989), which rule out saying what is obvious to all, their arguments will be incomplete most of the time, at least from the viewpoint of someone interested in logical analysis. Stating premises that are not doubted by any participant in a conversation is otiose. In real life, for example, many people present modus ponens and modus tollens arguments while omitting either the conclusion or the unconditional premise. In some cases, only the context shows that an argument instead of a conditional sentence is being presented, because both conclusion and nonconditional premise are omitted. Such terse statement of conditional arguments carries some risk, for one person's modus ponens is another's modus tollens. Consider, for example, Bertrand Russell's response ("I agree") to John Wesley's "If you give up belief in witches, then you give up belief in the Bible." (For discussion and other examples, see Salmon (1995).) Like others who study informal reasoning (e.g., Govier (1987) and Fogelin and Sinnott-Armstrong (1990)) we were interested in how to expose implicit features of conversational arguments, and we analyzed our subjects' conversations with this in mind.

Toulmin's analysis of arguments, as noted by Blair and Johnson (1987), Langsdorf (1990), and Freeman (1991), focuses on individual arguments as products rather than the processes that occur in an ongoing stream of argumentation. These authors' extensions of Toulmin's categories, however, do not address quite the same issues as our concern with dynamic shifts and complexities in conversations involving more than two participants. We wanted to be able to analyze arguments in which structure is substantially formed by the conversational give and take in the form of challenges, concessions, and attacks. Our studies noted frequent concessions to other's points of view, challenges to implicit as well as explicit contents, and subarguments that constituted organized attacks either on a 
single premise or a whole line of reasoning. Participants in the conversations we observed tried to persuade one another, but they also engaged in a fair amount of accommodation. All of these features appeared in segments (as brief as three and a half minutes) in the opening moves of conversations that we taped.

To characterize these arguments in the context of conversations, we adopted the standard logical vocabulary of argument, premise, and conclusion, while expanding that vocabulary to include other features as components of arguments, which we used to diagram the flow of arguments. In our diagrams, arguments are enclosed in boldface rectangles. Premises are symbolized by triangles and conclusions by rectangles. The challenges (symbolized by diamonds) that we recognize as integral to argumentation can take the form of questions asked, or doubts raised, or exclamations of surprise or disbelief. Challenges are usually directed to the arguments of others, but can be directed to one's own arguments, or to components of those arguments. Similarly, concessions (symbolized by hexagonal shapes) can be made to one's own or other's claims. Concessions involve yielding a point made in an argument, although sometimes the point may be anticipated or implicit rather than explicitly stated.

Attacks, more sustained and elaborate than challenges, are rarely directed at one's own position, except explicitly "for the sake of argument." An attack is an organized set of sentences directed against either an argument or one of its components. Less tentative than challenges, attacks are direct attempts to dismantle an opponent's argument and to show why the opponent's conclusions are unacceptable. Attacks form an essential part of the interaction between participants with opposing points of view. Some attacks are mini-arguments that try to discredit premises, other attacks try to break the connection between premises and the conclusions they are supposed to support. Attacks rarely occur within monologic arguments. Attacks are indicated in the diagrams by boldface oval shapes.

While some overlap exists between Toulmin's categories and ours, the two sets are not identical. His qualifiers, for example, indicate whether the claim follows with certainty or with some degree of probability in the presence of a particular warrant. Concessions, in contrast, always detract from the strength of an initial position. Similarly, Toulmin's rebuttals are not equivalent to concessions. Rebuttals, which guide the choice of a qualifier in Toulmin's (1964) scheme, determine whether a conclusion holds without exception. Since rebuttals mention conditions that would make a warrant inoperative they may be considered one form of concession, but not all concessions are rebuttals. For example, suppose that a statistical generalization concerning numbers of voters registered by party affiliation warrants the claim that the Democrats will win an election. The proponent of the claim might concede that a lower proportion of registered Democratic voters than Republican voters will go to the polls, but can maintain nevertheless that the Democrats will win. The statistical warrant for the claim is not rendered inoperative by the concession. When proponents concede points made by themselves, they are usually prepared to disarm the concession. When they concede in the face of an objection made by another, quick repairs may not be possible. In conversations, concessions keep open the possibility of other lines of arguments, and even in the face of challenges, allow arguments to proceed to their stated conclusions. It is not clear that rebuttals normally function in this way.

Participants in conversational arguments often restate their own or one another's points in a more forceful or more guarded manner, or simply restate a point to show agreement. They also offer examples to clarify points. Thus, our set of categories includes intensifier, less strong version, and example. Standard logical practice treats examples as background information instead of integral parts of an argument, and intensifiers or less strong versions of claims as redundant restatements of a premise or conclusion. As rhetoricians recognize, however, these features can contribute substantially to acceptance or rejection of a conclusion. We believe that the force of these components lies not just in their psychological importance but also in their cognitive and social features because they allow participants in a conversation jointly to refine and clarify the points initially made by one of them. In conversations, these utterances facilitate the cooperative construction of arguments.

\section{Recognizing Implicit Premises}

We distinguish two types of implied premises: factual (symbolized by hatched-line triangles) and theoretical (symbolized by shaded-line triangles). Implicit factual premises are subject to more or less direct empirical verification. We do not mean to imply that a given premise can always be clearly identified as factual or theoretical because many borderline cases exist. However, we can roughly distinguish claims more or less open to observational checks from those not easily accessible to observation or those that depend heavily on philosophical argumentation for their validation. Examples of factual claims that serve as implicit premises for our subjects include "Nuclear power is not the only alternative to fossil fuel," "Most nuclear plants are well maintained," and "Human operators are prone to error." Note that some of these factual premises are low-level empirical generalizations. We could affirm the presence of these premises because not only did they "make sense," but at later points in a conversation, they were referred to or challenged as if they had been stated. We were vindicated in attributing such implicit premises to participants because when one participant raised a challenge to an unstated premises, the others showed no puzzlement or surprise, and did not protest that the claim had not been made.

Theoretical premises are so-called because they are bound up with broad theories of morality, economics, or physics, and are not the sort of beliefs that can be tested directly against empirical data. For example, the claim that "All other things being equal, the least expensive alternative should be chosen", which carries both moral and economic weight, was judged to be an implicit component in one conversation that we examined. "Theoretical" implicit premises, in contrast to factual implicit premises, were neither referred to nor challenged by any participants 
in the conversation. We hypothesize that the lack of later reference to theoretical premises was understandable because such assumptions form part of the shared cultural background of all of the participants. The participants were all so deeply committed to these principles that questions about them do not normally arise. The subjects could be made aware of the assumed principles by asking whether they held such views, or by challenging the views, but otherwise they would be unlikely to express those principles.

Some members of our research group designed experiments to test the validity of the factual and theoretical premises we ascribed to discussants. M. Holowchak showed the taped conversations to other subjects with similar backgrounds, stopped the tapes at points in the argument where we believed that an implicit premise was operative, and asked the subjects whether the speaker on the tape believes the imputed premise. Responses to this experiment were sensitive to the way the questions were framed, but support our method of deriving implied premises (Holowchak \& Resnick, 1992).

\section{Representations of Conversations}

Our categories for analyzing conversational reasoning are demonstrated in the analysis of a segment of conversation described in the following transcript and diagram. In addition to the symbols already described above, hatched-line rectangles indicate implicit conclusions, plus signs $(+)$ indicate intensifiers, minus signs (-) indicate less strong versions of a claim, eg indicates an example, tilde $(\sim)$ a negation, and the equal sign $(\Rightarrow)$ an equivalent sentence. Three dots (. . .) indicate ellipses, which may mark unfinished sentences or breaks that occur when one participant begins a sentence and another completes it. The arrows connect premises with conclusions $(\rightarrow)$, attacks with what they attack $(\rightarrow)$, and sentences with their negations, intensifiers, and so forth $(\rightarrow)$.

In one protocol, after an initial round of deciding who will go first, $\mathrm{C}$ takes a stand against nuclear power (C4.1) because it is not really cleaner than fossil fuels (C4.2). These two components could be analyzed as "claim" and "datum" on Toulmin's model. Note, however, what happens next. Instead of asking for a warrant, $\mathrm{B}$ denies $\mathrm{C} 4.2$ (B6.1), restricting his claim to atmospheric pollution. In the next breath (B6.2), however, he concedes the greater danger from nuclear waste. The concession is taken up by $\mathrm{C}$, who emphasizes $\mathrm{B} 6.2$ by noting the long life of nuclear waste $(C 7.1)$ and the impossibility of disposing of the waste (C7.2). He then concedes that this state of affairs is dependent on present technology (C7.3). Participant B now responds by saying that acid rain lasts a long time too (B8). We interpret this as a challenge to a claim that has not been stated (C7.1i) - the " $\mathrm{i}$ " indicates its implicit nature. The response of B to C makes sense only if participants in the conversation understand that C's claim about the longevity of nuclear waste was a comparative judgment between nuclear waste and fossil-fuel waste.
Identifying implicit premises is problematic for those attempting to understand and evaluate arguments. With sufficient generosity in attributing implicit premises, any argument can be judged correct. So what allows us to attribute a premise or withhold attribution? If some implicit premise is clearly intended, how do we identify its precise content? In other words, how can we distinguish a correct enthymeme from an incorrect argument? When we realize that in conversations we recognize implicit premises-at least implicit factual premises-through challenges and concessions, then the importance of representing these components of arguments becomes clear.

Challenges can also be used to shift the ground of the argument. To deal with the B's challenge, C redirects the argument and attacks the unfavorable comparison of fossil fuel with nuclear fuel. He begins by conceding that acid rain is a problem (C9.1), but disarms his concession by arguing that if you reduce emission then acid rain can be reduced (C9.2a . . C9.2c). This is an explicitly stated warrant in Toulmin's terms. Participant $\mathrm{C}$ also provides the datum that present technology can reduce emission (C9.3). The implicit conclusion, not stated because of its obviousness when both datum and warrant are presented explicitly, is that acid rain can be reduced.

Notice, here, that the issue of the longevity of acid rain has not been addressed; instead $\mathrm{C}$ argues that the amount of acid rain can be reduced. No one challenges this shift, perhaps because they all agree that if acid rain is reduced sufficiently, the environment can absorb what is left without permanent damage. In other words, they probably share the assumption that acid rain poses a threat only if it continues at high levels. Having addressed B's challenge, C drops the topic of acid rain, and turns to the difficulty of disposing of nuclear waste (C9.4) Although $\mathrm{C}$ continues to move against nuclear power, the argument has been reshaped by B's challenges.

Cooperation and agreement among participants is evident at the end of the first minute, when $B$ finishes C's sentence (B10), A agrees (A11), and C repeats what B said (C12.1). Agreement is short-lived, however, for $\mathrm{C}$ asserts the unreliability of safe burial (C12.2), and B challenges him by appealing to a monetary solution $(\mathrm{C} 13 \mathrm{a}, \mathrm{c})$. Then A challenges B's notion of safety (A14) and $\mathrm{C}$ also challenges $\mathrm{B}$ by referring to New Mexico (C17). (Participants were aware of publicity about water leakage in a New Mexico site that had earlier been selected as a safe place for burying nuclear waste.) Participant B answers these challenges by stating the conditions under which safe burial is possible $(\mathrm{B} 18 \mathrm{a}, \mathrm{c})$.

Please see Figures $2 a$ and b on pp. 12-13.

The statements about safe burial elicit an attack from $\mathrm{C}$, who notes that a nuclear burial area must remain undisturbed for 100,000 years (C19), and that this cannot be guaranteed (C21.1). However, $\mathrm{C}$ softens his factual claim with a concession ("I don't think . . . it doesn't seem possible to me" (C21.2)). This concession does not correspond to one of Toulmin's rebuttals because although it

Please see Figures 1 and $b$ on pp. 10-11. 


\section{Participant A}

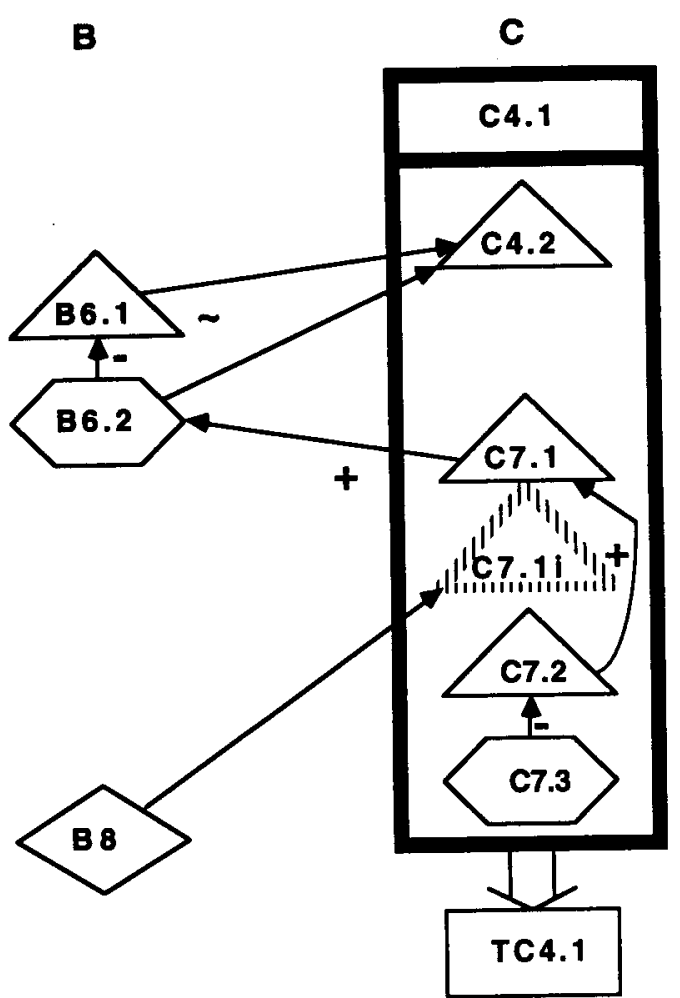

C4.1: Well, uh is, is nuclear, I'm against it.

C4.2: Is nuclear power really cleaner that fossil fuels? I don't think so.

\section{As: You don't think, I think//}

B6.1: In terms of atmospheric pollution I think that..the waste from nuclear power, I think it's..much less than fossil fuels.

B6.2: but the waste that is there of course is quite dangerous $/ /$

C7.1: It's gonna be here for thousands of years,

C7.2: you can't do anything with it.

C7.3: I mean, right now we do not have the technology as//

B8: Acid rain lasts a long time too you know
Figure 1b

\section{TC4.1: NP should not be used.}

C7.li: Nuclear waste lasts longer than fossil fuel waste. 


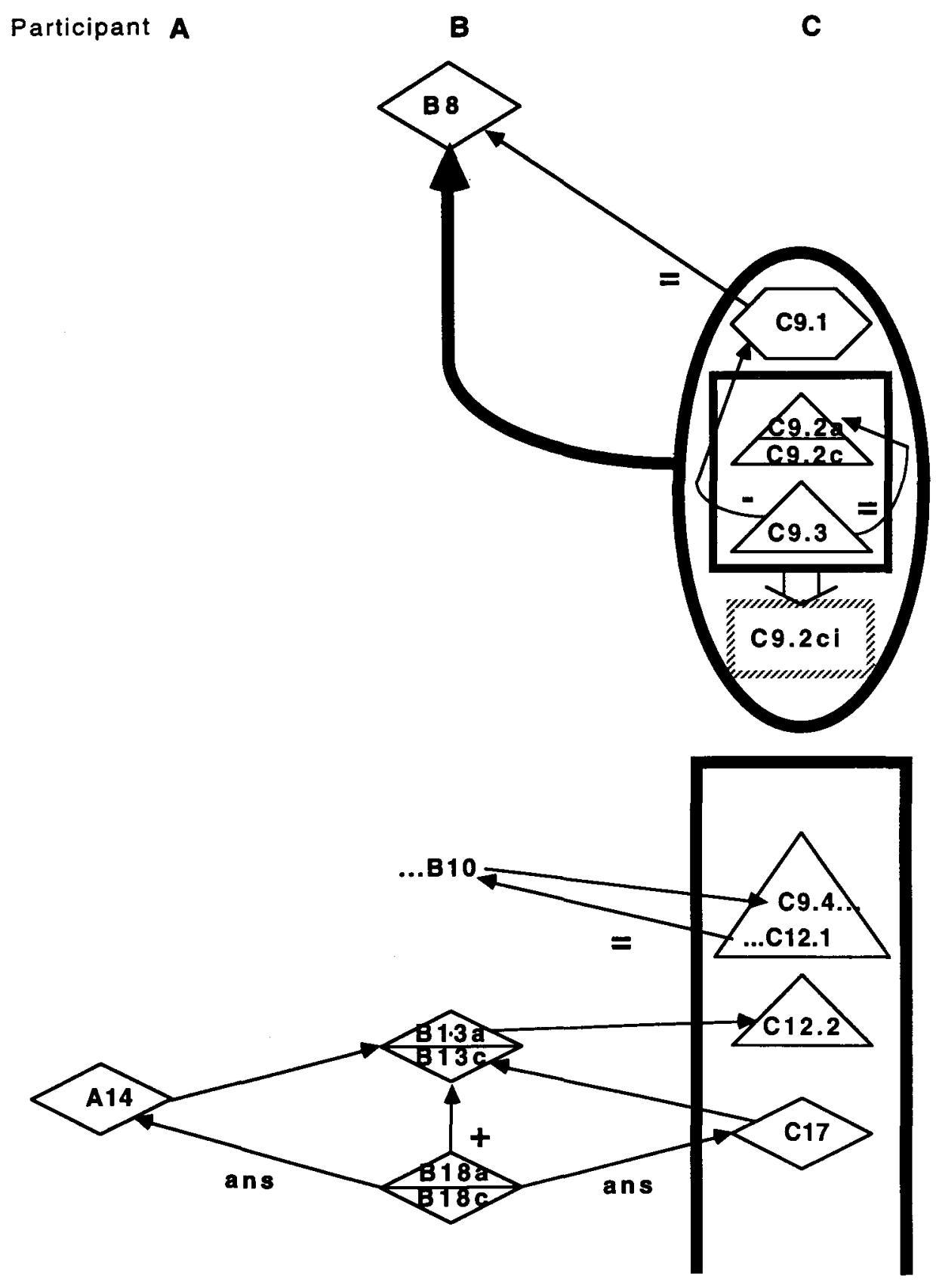

Figure 2a

\section{Figure $2 b$}

B8: Acid rain lasts a long time too you know

\section{C9.1: That's true}

C9.2a: but if you reduce the emissions of fossil fuels

C9.3: which you can do withi, uh, certain technology that we do have right now, um, such as scrubbers and such,

C9.2c: you can reduce the acid rain,

C9.2ci: You can reduce acid rain.

C9.4: with the nuclear power you can't do any, I mean nuclear waste you cannot do anything with it except//

\section{B10: bury it}

A11: m-hm

C12.1: bury it

C12.2: and then you're not even sure if its ecologically um.that the place you bury it is ecologically sound.

B13a: I, I think if if enough money is spent B13c: it can probably be put in a reasonably safe area

A14: reasonable for what? (laugh)

C15: well/

B16: well//

C17: Well we just heard that out in New Mexico/l

B18a: If something , something is either a half or three quarters of a mile underground in a geologically solid area,

B18c: no earthquake or anything like that is going to disturb it and get it into the water table 
weakens the premise, the (implicit) conclusion, which is a denial of B18, is not qualified by this concession.

Again, agreement is reached as A and B concede that not enough is known to guarantee a geological site safe for nuclear burial (A23, 25, 27), (B28), and B begins a new line of argument by asking what happens when we run out of fossil fuel (B30).

Please see Figures 3 a and b on pp. 16-17.

In several ways, the conversational segment described above is typical of conversations in which reasoning occurs:

(1) Although more than two persons are participants in the conversation, usually two of them are engaged in a dialogue while the third participates only incidentally. At different points in the conversation, different participants play the role of the "third." (See also Brashers and Meyers (1989); Canary, Ratledge and Seibold (1987); and Seibold et al. (1981).)

(2) Grice's conversational maxims concerning relevance and not saying too much are operative. Once participants reach agreement on an issue they do not belabor the point; conversation moves ahead. While participants are not loathe to voice disagreement, they soften their challenges and attacks with concessions to the opponents' views, partial agreements, and disclaimers to their own knowledge. These moves show a spirit of cooperation and willingness to let the conversation follow different directions. (See also Jackson and Jacobs (1980).)

(3) The diagrams show that challenges and concessions contribute significantly to structure these co-constructed arguments. Although one person might take the lead in presenting an argument, as $\mathrm{C}$ does in our example, the leader cannot ignore challenges from other participants. These challenges, and the concessions or other responses that they evoke, reveal implicit premises and result in shifts of ground for the argument. On these points we find Toulmin's scheme of categories deficient for analyzing conversational reasoning. (See also Jacobs and Jackson (1981) and Schiffrin (1985).)

Toulmin's discussion of warrants and backings suggests that these implicit premises are always universal or statistical generalizations that would support syllogistic or quasi-syllogistic arguments. Our analysis of conversations suggests greater complexity. Along with others-e.g., Clark (1992)-who study conversations, we believe that the background of any conversation is constituted by a collection of ideas that are both relevant to the topic of conversation and are shared by the speakers. This collection of ideas is formed both from what is said in the conversation and from beliefs that the speakers are willing to attribute to one another on the basis of general background knowledge. The maintenance of this common ground allows conversations to flow smoothly. During the course of the conversation, the ground can expand or contract. Each participant's statements constitute support for the explicit and implicit ascription of beliefs to them by others in the conversation.
Occasionally, a participant tries to add some belief to the common store, and finds this move rejected by the other participants. For example, in one of our protocols, a participant insists, "If you go for nuclear power ... first of all you're not really considering the effects it's going to have on the future." Another participant resists by saying, "Well I do! No, I do consider the effects it has on the future." In this case, when one participant tried to add a generalization about those who favor nuclear power to the common store of beliefs, she was thwarted by another, who presented herself as a counterexample to the generalization. After this rejection of the generalization as part of the shared background, the conversation proceeded smoothly.

In contrast to the clarification achieved in the instance just discussed, sometimes the speaker and listener in a conversation interpret an ambiguous statement differently, and multiple conversational grounds develop. In the third minute of the conversation described in this paper, B discusses his concerns about energy options when fossil fuels are depleted (B30). Participant $\mathrm{C}$ responds by bringing up alternative sources, such as solar power (C33). Then $C$ says " $[R]$ ight now nuclear power accounts for 18 per cent of the total energy. It, it supplies 18 per cent or what we use, what the United States uses, so that's, I mean ..." (C35). At this point, $B$ interrupts $C$, and appears to believe that C's point was that nuclear power only accounts for 18 per cent, which is not enough to prevent our running out of fossil fuel. We believe that $B$ interprets $C$ in this way because $B$ is primarily concerned with the limited supply of fossil fuels. In the diagram (Figure 4), this interpretation is marked as C's implied conclusion according to B (Ca35i (B)).

In response to $\mathrm{C}, \mathrm{B}$ describes how nuclear power could be developed to account for "a whole lot more" of our energy (B36). However, alternative energy sources, rather than the shortage of fossil fuel, appear to be C's focal concern. We believe that if $\mathrm{C}$ had been able to complete his sentence, he might have made it clear that he meant "Even now alternative sources could compensate for current nuclear underst. This is the implied conclusion that we believe that both $\mathrm{A}$ and $\mathrm{C}$ understand, and we include it in our diagram as well (Ca35i (A\&C)).

The disparity in the conversational grounds is brought out by A's seemingly inane response to B's argument about increasing nuclear output: "Is that what we're, if that's what we're discussing ..." (A40) and the unconnected and unclear remarks that follow. The conversation comes to a standstill when two of the participants realize that their background assumptions are not coherent. In this case, no participant pinpoints the belief that has caused the breach, and so they are unable to correct it. The participants are lost for a few seconds. In an apparent effort to restore conversational flow, $\mathrm{B}$ repeats his argument $(\mathrm{B} 45 \mathrm{a}, \mathrm{c})$.

Please see Figures 4 a and $b$ on pp. 18-19.

Psychologists believe that we can best understand mechanisms by examining the situations in which they break down. A smooth flow of conversation is certainly the norm, so we were fortunate to observe this unusual case in which the 
B18a: If something, something is either a half or three quarters of a mile underground in a geologically solid area,

B18c: no earthquake or anything like that is going to disturb it and get it into the water table

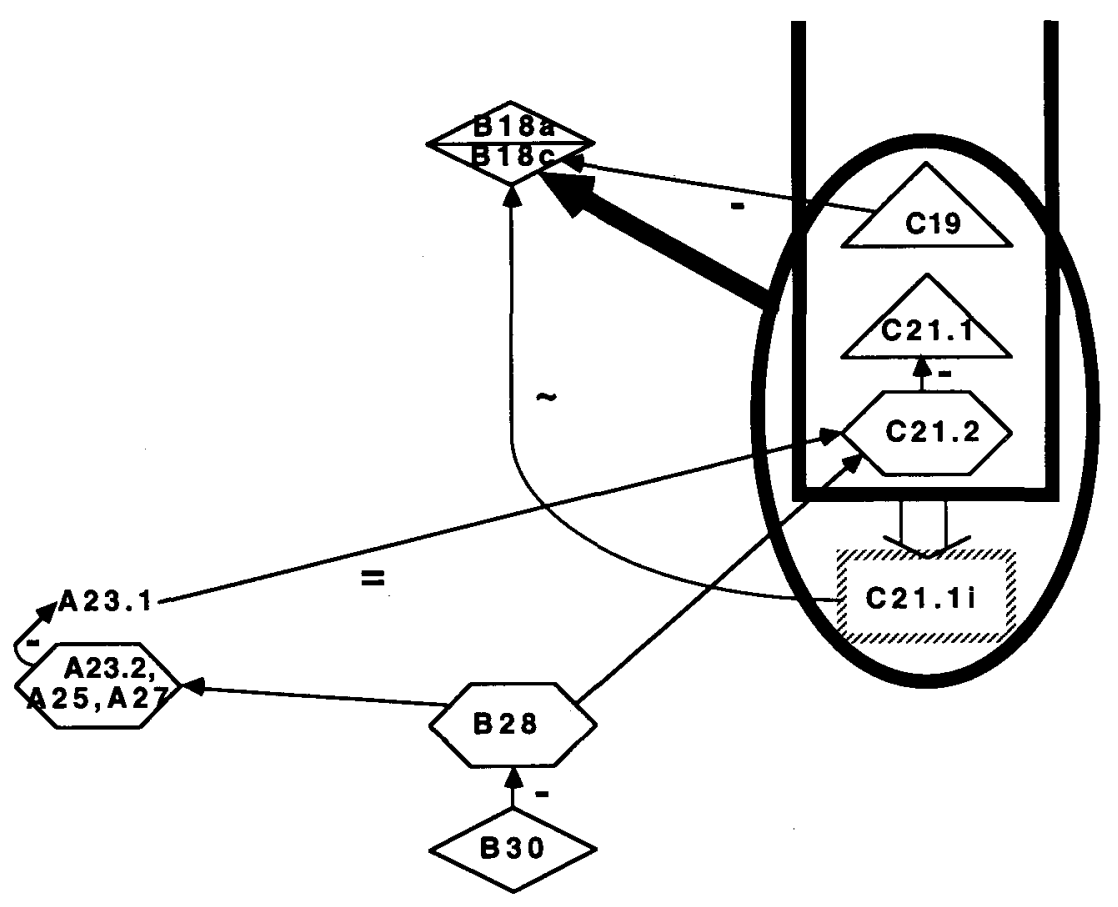

C19: You see but the only problem is the burial is gonna have to be for a hundred of thousands of years//

B20: $\mathrm{m}-\mathrm{hm}$

C21.1: and you cannot guarantee that anything is gonna be geologically safe for a C21.1i: It is not true that $B 18$. hundred thousand years.

C21.2: at least I don't think I can do that, or maybe even, maybe you can but it doesn't seem possible to me

B22: m'hm

A23.1: Well I suppose it's, a problem..

A23.2: I really, I really don't know/l

C24: right

A25: that much about geology//

B26: $\mathrm{m}-\mathrm{hm}$

A27: Enough what uh how long things stay stable for..you know

B28: That, that's a good point. I don't I

don't know how much will be moved around in a hundred years either//

C29: yeah

B30: but the other...but on the other side of the coin, what happens when we run out of fossil fuels, then what'll we do? 
Participant A

B

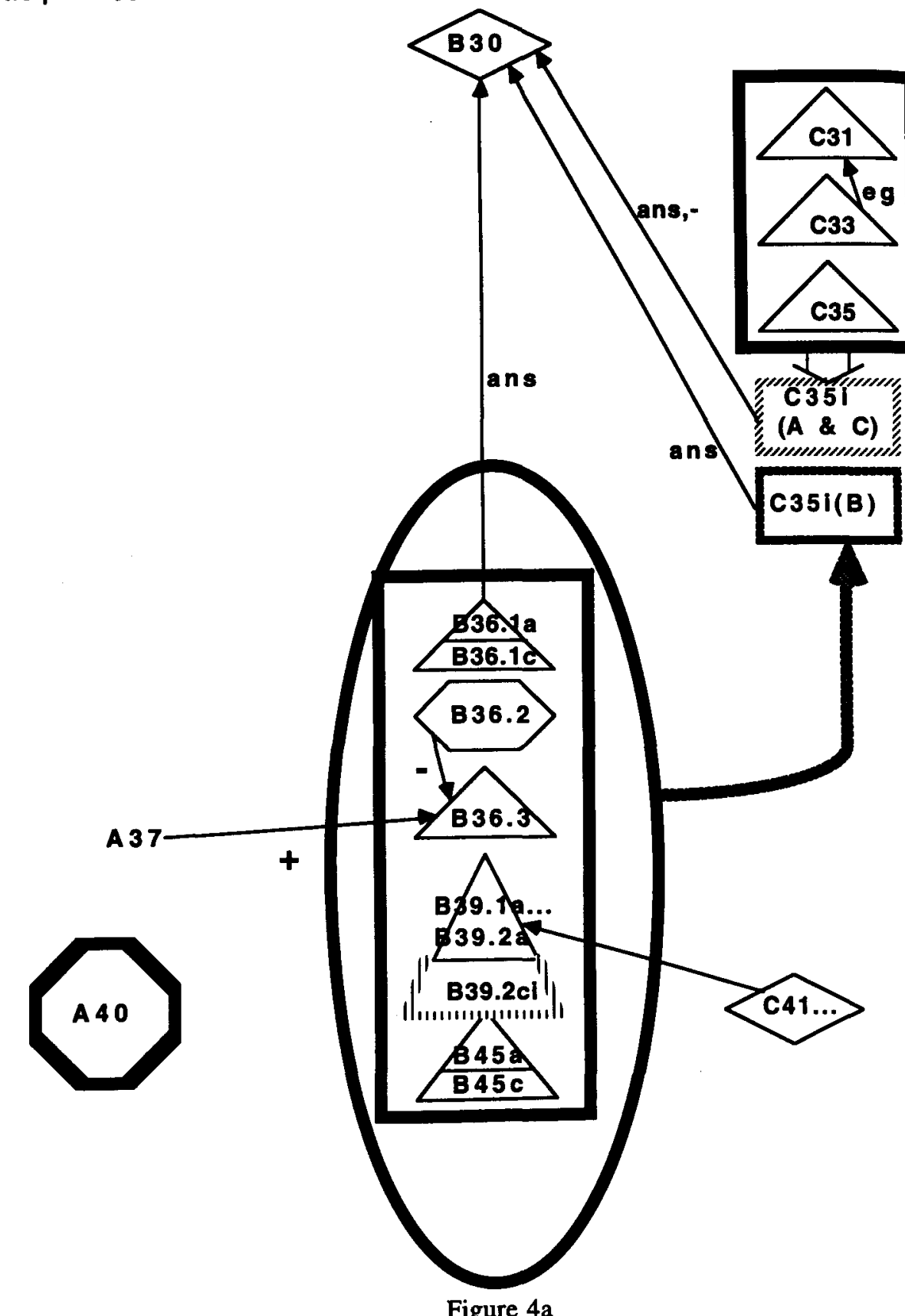

Figure 4a
C

Figure 4b

B30: but the other...but on the other side of fossil fuels, then what'll we do? the coin, what happens when we run out of

C31: Well there, there are alternative, alternative fuels that can be developed, I believe/l

B32: $\mathrm{m}-\mathrm{hm}$

C33: solar

A34: right, yeah

C35: that that seems to be the most, I mean right now nuclear power accounts for $18 \%$ of the total energy. It, it supplies $18 \%$ of what we use, what the United States uses, so that's, I mean/I

B36.1c: I think it could account for a whole lot more

B36.1a: if, they, if the government and the various electrical companies were to actually invest in nuclear power and develop all the newer techniques

B36.2: I, uh, I may be wrong

B36.3: but I understand that some of the newer, um, fission or fusion techniques don't make nearly as much waste and not nearly as high level as it had in the past//

A37: with the fusion research//

C38: well//

B39.1 a: and if that were to be developed

B39.2a: and the amount of waste were, was to be brought down to, you know say $30 \%$ of what it is now/l

A40: Is that what, I think what, what we're discussing//

C41: yeah but even if you/l

B42: then you could have/l

A43: right now is just what's happening right now, it's not what/l

C44: yeah in the //

B45a: well what $I m$ saying is that then if that were to happen

B45c: then you could have nuclear power counting for probably $80 \%$, and have it going on with little or no waste
C35i (A and C): Even now alternative sources could compensate for current nuclear output.

C35i (B): Nuclear power only accounts for $18 \%$ which isn't enough to keep us from running out of fossil fuels.

B39.2ci: Nuclear power would be safe. 
conversation came apart. It would be nearly impossible to deliberately engineer such a breakdown in a laboratory setting. The strong effects of the loss of one largely overlapping conversational ground for all three speakers indicates how much conversational progress depends upon the careful maintenance of the common ground. This state of affairs can be illustrated in a relatively straightforward way using our representational system. Because the system is flexible enough to cover easily an unusual situation such as this, we believe it to be generally useful and powerful.

\section{Conclusion}

This study of reasoning in conversation throws additional light, we believe, on reasoning as a social activity. The social context in which the reasoning takes place influences-but does not totally determine-which unstated assumptions are operating, what must be explicitly stated as a premise and how the evidence relates to the conclusion. Participants negotiate these issues in the course of conversation through challenges and concessions, which seem essential features of the activity. Moreover, these patterns are not a special feature of conversations among relatively well educated college students. Data on very young children, reported by Pontecorvo (1987) and others, can be analyzed in the same way. Pontecorvo's data offer some support for the view that reasoning as a social activity precedes and guides the solitary exercise. If this is correct, then teachers would be wise to exploit features of socially shared reasoning when they try to improve their students' skills in reasoning.

The categories and diagrams we devised on the basis of our empirical studies are useful for following the flow of conversations and observing patterns of interaction and shifting grounds. In addition, they permit quantitative analyses of features of conversations that might be relevant to appraisals of the quality of arguments constructed. The coding system that is described here could be expanded to include additional categories or subdivisions of the categories present. For example, one could draw a distinction between "genuine" concessions, in which some point is yielded and "strategic" concessions, in which the concession does not really involve giving up a point, but instead buys time for another try or merely keeps the conversation going. Similarly, the coding system could be compressed if less detailed analysis would serve the purpose at hand. While acknowledging again that the value of any system of classification and coding depends on the purposes to which it is put, we nevertheless believe that the broad scope and flexibility of the system elaborated in this paper allows comparisons and contrasts among larger pieces of discourse than the analyses offered by other authors, such as Freeman (1991), Jackson and Jacobs (1989), Schiffrin (1985), and van Eemeren, Grootendorst, and Kruiger (1987) who have developed and expanded Toulmin's original set of categories for the analysis of arguments.

\section{Acknowledgements}

The authors gratefully acknowledge the support of the Andrew W. Mellon Foundation. This work was done in cooperation with the members of the Pragmatics Research Group, headed by Lauren Resnick, at the Learning Research and Development Center of the University of Pittsburgh. We thank Professor Resnick and other members of her group for their advice and criticism, as well as the editors and anonymous reviewers for Informal Logic. We are also grateful to Madeline Muntersbjorn for her help in videotaping and transcribing the discussions.

\section{References}

Blair, J. A. and R. Johnson (1987). Argumentation as Dialectical. Argumentation 1: 4146. 2nd ed. McGraw: New York.

Brashers, D. and R. Meyers (1989). Tag-team Argument and Group Decision-making: A Preliminary Investigation. In B. E. Gronbeck (ed.), Sphere of Argument, pp. 542-550. Annandale, VA:Speech Communication Association.

Canary, D., N. Ratledge and D. Seibold (1987). Argument Structures in Decision-making Groups. The Southern Speech Communication Journal 53: 18-37.

Clark, H. H. (1992). Arenas of Language Use. Chicago: University of Chicago Press.

Fogelin, R. and W. Sinnott-Armstrong (1990). Understanding Arguments: - An Introduction to Informal Logic, 4th ed. Harcourt Brace College Publishers, Fort Worth and New York.

Freeman, J. (1991). Dialectics and the Macrostructure of Arguments. Berlin and New York: Foris Publications.

Govier, T. (1987). Problems in Argument Analysis and Evaluation. Dordrecht: Foris.

Grice, J. P. (1989). Studies in the Way of Words. Cambridge: Harvard University Press.

Henle, M. (1962). On the Relation between Logic and Thinking. Psychological Review 69: 366-378.

Holowchak, M. and L. Resnick (1992). Unpublished manuscript: The Role of the Unstated in Conversational Discourse. LRDC, University of Pittsburgh, Pittsburgh, PA 15260.

Jackson, S. and S. Jacobs (1980). Structure of Conversational Argument: Pragmatic Bases for the Enthymeme. Quarterly Journal of Speech 66, 251-265.

Jacobs, S. and S. Jackson (1981). The Collaborative Production of Proposals in Conversational Argument and Persuasion: A Study in Disagreement Regulation. Journal of the American Forensic Association 18, 77-90.

Jacobs, S. and S. Jackson (1989). Building a Model of Conversational Argument. In B. Dervin, L. Grossberg, B. O'Keefe, and E. Wartella (eds.), Rethinking Communication, Vol. 2, pp. 163-171.

Jacobs, S. and S. Jackson (1992). Relevance and Digressions in Argumentative Discussion: A Pragmatic Approach. Argumentation 6, 161-172.

Johnson-Laird, P. (1983). Mental Models. Cambridge: Harvard University Press.

Kitcher, P. (1991). Persuasion. In Pera, M. and W. R. Shea (eds.), Persuading Science. The Art of Scientific Rhetoric, pp. 3-27. USA: Science History Publications. 
Kitcher, P. (1992). Authority, Deference, and the Role of Individual Reason. In McMullin, E. (ed.), The Social Dimensions of Science, pp. 244-271. Notre Dame: University of Notre Dame Press.

Kuhn, D., M. Weinstock and R. Flaton (1994). How well do jurors reason?: Competence dimensions of individual variation in a juror reasoning task. Psychological Science 5: 289-296.

Langsdorf, L. (1990). On the Uses of Language in Working and Idealized Knowledge. Argumentation 4: 259-268.

Leff, M. (1978). In Search of Rhetorical Theory. Central States Journal 29:73-91.

Longino, H. (1992). Essential Tensions-Phase Two: Feminist, Philosophical, and Social Studies of Science. In McMullin, E. (ed.), op. cit., pp. 198-216.

Pontecorvo, C. (1987). Discussing for Reasoning: The Role of Argument in Knowledge Construction. In De Corte, E., J. G. L. C. Iodewijks, R. Parmentier and P. Span (eds.), Learning and Instruction. A Publication of the European Association for Research on Learning and Instruction, pp. 71-82. Oxford/Leuven: Leuven University Press.

Rescher, N. (1977). Dialectics: A Controversy-Oriented Approach to the Theory of Knowledge. Albany: State University of New York Press.

Resnick, L., M. Salmon and C. Zeitz (1991). The Structure of Reasoning in Conversation, Proceedings of the Cognitive Science Society Annual Meeting, pp. 388393.

Resnick, L., M. Salmon, C. Zeitz, S. Wathen and M. Holowchak (1993). Reasoning in Conversation. Cognition and Instruction 11:347-364.

Salmon, M. (1995). Introduction to Logic and Critical Thinking, 3rd ed. New York: Harcourt Brace College Publishers.

Schiffrin, D. (1985) Everyday Argument: The Organization of Diversity in Talk. In T. A. van Dijk (ed.), Handbook of Discourse Analysis, Vol. 3, pp. 35-46.

Seibold, D., R. McPhee, M. Poole, N. Tanita and D. Canary (1981). Argument, Group Influences, and Decision Outcomes. In G. Zeigelmuller and J. Rhodes (eds.), Dimensions of Argument, pp. 663-692. Annandale, VA: Speech Communication Association.

Toulmin, S. (1964). The Uses of Argument (2nd ed.). Cambridge: Cambridge University Press.

Toulmin, S., R. Rieke and A. Janik (1984). An Introduction to Reasoning (2nd ed.). New York: Macmillan.

van Eemeren, F. and R. Grootendorst (1992). Argumentation, Communication, and Fallacies: A Pragma-dialectic Perspective. Hillsdale, NJ: Erlbaum Associates.

van Eemeren, F., R. Grootendorst and T. Kruiger (1987). Handbook of Argumentation Theory. Dordrecht: Foris.

Voss, J. (1991). Learning to Reason via Instruction in Argumentation. Learning and Instruction 16:337-350.
Walton, D. (1992). Plausible Argument in Everyday Conversation. Buffalo: State University of New York Press.

MERRILEE H. SALMON

HISTORY \& PHILOSOPHY OF SCIENCE

COLLEEN M. ZEITZ

LEARNING RESEARCH \& DEVELOPMENT CENTER

UNIVERSITY OF PITTSBURGH PITTSBURGH, PA 15260 